\title{
Motivação e liderança: um trabalho em equipe nas organizações
}

\author{
Marcelo Augusto Loenert ${ }^{1}$
}

\section{Introdução}

As práticas de motivação e liderança estão sendo cada vez mais aplicadas nas organizações. Várias mudanças têm ocorrido ao longo do tempo com relação aos estilos de liderança. A prática tradicional de gerenciamento considerava o colaborador como um elemento importante dentro da organização, como uma pessoa que possuía fronteiras estabelecidas no seu cargo e evoluía de acordo com seu desempenho individual. Falhas eram motivos para punições e realização de treinamento técnico excessivo, transformando-se em organizações que geravam individualismo, ambiente conflitante, comunicação deficiente, egoísmo e ganância. Desta forma, perdiase a noção do objetivo principal da organização, considerado a produção, a lucratividade e uma visão voltada para os clientes.

Atualmente as organizações estão buscando um relacionamento melhor entre as pessoas, incentivando o trabalho em equipe, a harmonia no grupo e enfatizando a importância dos líderes nestes trabalhos. As organizações tendem a buscar o EMPOWERMENT, ou seja, dar autonomia aos colaboradores e força no trabalho em conjunto. O gerente não é necessariamente o líder, mas sim qualquer integrante da organização que possa conduzir ou facilitar o desempenho das equipes para um determinado objetivo.

\section{A influência da motivação no comportamento das pessoas}

Os estudos sobre motivação e liderança já acontecem há muito tempo nas organizações. A Administração Científica de Taylor e seus seguidores baseavam-se no "homo economicus", cujo estudo tinha como base apenas 0 comportamento do homem motivado pelo dinheiro, recompensas salariais e materiais do trabalho. Assim sendo, toda abordagem clássica da Administração era voltada para este modelo de motivação. Haviam conflitos entre

\footnotetext{
${ }^{1}$ Professor da Faculdade Cenecista Presidente Kennedy. Núcleo de Estudos Pedagógicos e Administrativos. Campo Largo-PR.
} 
empregados e engenheiros devido aos estudos de tempos e movimentos realizados pelos engenheiros da época.

Segundo CHIAVENATO (1993), a experiência de Hawthorne veio para mostrar que o pagamento ou salário, mesmo quando generoso, não é o único fator decisivo na satisfação do trabalhador dentro da situação de trabalho. Com a teoria das Relações Humanas, passou-se a estudar a influência da motivação no comportamento das pessoas.

Percebeu-se a necessidade em se considerar a cultura da empresa, tão importante quanto à produtividade e a qualidade, assim como utilizar os talentos humanos em conjunto.

Para o líder é necessário sentir as pessoas, suas necessidades, aspirações e anseios. Segundo CABRAL (WWW.CRA-RJ.ORG.BR) "Temos que conciliar os interesses das organizações com os das pessoas que trabalham nela, objetivando criar um ambiente favorável ao desenvolvimento". Portanto, em qualquer estilo de liderança que venha a ser aplicado é necessário o comprometimento de toda organização, do contrário será difícil implantar um método que possa efetivamente dar certo.

Quanto às características de um líder, é possível afirmar que líder é aquele que coloca o desempenho da equipe em primeiro plano, reconhece e tem humildade para pedir ajuda, não buscando resultados com propósitos individuais. Segundo OLIVEIRA e PAULETTI (WWW.CTAI.RCT-SC.BR), "A performance da equipe quase sempre depende do líder ser capaz de atingir um equilíbrio crítico entre fazer as coisas pessoalmente e deixar que outras pessoas façam".

\section{Condições necessárias para uma boa liderança de equipe segundo Oliveira e Pauletti ( www.ctai.rct-sc.br)}

a) Manter a relevância e o significado do propósito, das metas, da missão e da abordagem da equipe:

Embora o líder deva ser um participante plenamente envolvido com o trabalho da equipe, possa e deva contribuir, ele deverá manter uma certa distância em virtude de ter sido escolhido para função de líder. As equipes 
esperam que seus líderes possam fazer uso dessa perspectiva e distância para ajudá-las a esclarecer e se comprometer com sua missão, suas metas e abordagem. Desta forma, geralmente preferem que seus líderes não ultrapassem este limite. Certamente, na qualidade de participante habitual da equipe, um líder tem o direito de fazer quaisquer sugestões, de caráter geral ou específico. Atuando como líder, comentários e sugestões de outros membros poderão ser entendidos como comandos, pois isso ocorre no contexto empresarial onde os subordinados estão condicionados a ouvir ordens quando se trata da palavra de um chefe. Se os líderes fizerem muitas especificações a respeito do propósito, metas e abordagem, estarão utilizando a distância da equipe segundo os moldes hierárquicos, em vez de utilizar os moldes de equipe. Porém ao fazê-lo, obterão o cumprimento dos "seus" propósitos e estarão perdendo o senso de compromisso em relação ao propósito da equipe. Isto ocorre principalmente durante a fase inicial dos trabalhos de equipes potenciais, quando todos os olhos e ouvidos estão voltados à forma de como o líder utilizará sua autoridade para construir uma equipe.

b) Construir senso de compromisso e confiança:

Como função de líder de equipe é preciso trabalhar no sentido de construir o senso de compromisso e confiança de cada participante e da equipe como um todo. Existe uma diferença importante entre senso de compromisso, responsabilidade individual e senso de responsabilidade mútua. O líder deve procurar dar a sua equipe e aos indivíduos um reforço positivo e construtivo, evitando as intimidações. No contexto organizacional é fácil coagir as pessoas, porém com o decorrer do tempo, este tipo de liderança torna-se saturada, fazendo com que as pessoas percam o entusiasmo e a iniciativa.

O reforço positivo e construtivo impulsiona o senso de responsabilidade e confiança mútua, essencial para a performance da equipe.

c) Fortalecer o conjunto e o nível de conhecimentos:

Equipes flexíveis e de alta performance devem ser compostas por pessoas com todos os conhecimentos necessários relativos a assuntos técnicos, funcionais, solução de problemas, tomada de decisões, 
relacionamento interpessoal e teamwork. Portanto, os líderes devem encorajar os participantes a assumir os riscos fundamentais para o crescimento e desenvolvimento. Devem também desafiar continuamente os membros da equipe mediante mudanças em suas atribuições e seus papéis. Nenhuma equipe alcança suas metas tendo uma grande lacuna de conhecimentos em relação ao seu objetivo de performance.

d) Gerenciar relacionamentos com pessoas de fora, inclusive removendo obstáculos:

Pessoas dentro e fora das equipes esperam que seus líderes atuem no gerenciamento de grande parte dos contatos e relacionamentos da equipe com o restante da organização. Isto requer que os líderes sejam capazes de comunicar com eficácia o propósito, as metas e a abordagem da equipe.

e) Criar oportunidades para outros:

O líder não deve aproveitar as melhores oportunidades, atribuições e créditos para si próprio. De fato, o ponto crucial do desafio do líder é criar oportunidades de performance para a equipe bem como para seus participantes. Entretanto, sair do caminho para proporcionar oportunidades para outros significa abdicar de responsabilidades pela direção, pelo monitoramento e pelo controle.

f) Realizar trabalho real:

Todos os participantes de uma equipe real, inclusive seu líder, executam trabalho real em quantidades aproximadamente equivalentes. Líderes de equipes mantêm uma certa distância do grupo em função da sua posição, mas não fazem uso desta distância "para simplesmente se acomodar e tomar decisões". Os líderes devem contribuir da forma que o grupo necessitar, exatamente como qualquer um dos seus participantes. Além disso, líderes de equipes não delegam trabalhos desagradáveis aos outros. Quando riscos pessoais são altos ou se torna necessária à execução de um "trabalho braçal", o líder da equipe deve tomar a dianteira. 


\section{Princípios básicos de liderança}

Segundo OLIVEIRA e PAULETTI (WWW.CTAI.RCT-SC.Br) o líder deve proporcionar um crescimento relevante para a equipe, onde as habilidades técnicas e humanas trabalhem em harmonia. As organizações estão exigindo que os perfis de seus funcionários tenham características de um líder, pois cada vez mais as pessoas terão que dirigir, motivar e treinar, bem como delegar responsabilidades e autoridade.

De acordo com HERSEY E BLANCHARD (1986), a seguir alguns princípios básicos de liderança:

a) Dirigir:

É dar um direcionamento, uma rota para que a equipe possa guiar-se com o objetivo de atingir a missão proposta pelo líder no consenso de todos. $O$ líder deve ser capaz de criar o sentido e a razão da existência da equipe. É de fundamental importância criar desafios e dar autonomia para que em conjunto as decisões sejam implementadas.

Uma equipe mantém-se motivada quando para ela está claramente definido os objetivos e metas a serem alcançadas e a verificação da viabilidade do cumprimento destas metas. Por isso, o líder é responsável por manter a comunicação clara e atualizada à equipe, informando a todos os propósitos do grupo e as ações a serem tomadas.

O próprio grupo, conduzido pelo líder, deve avaliar seus recursos humanos, financeiros e tecnológicos, diagnosticando a situação com o objetivo de elaborar um plano de ações. Nesta etapa a equipe revê sua missão e identifica claramente o problema central e suas barreiras. O líder deve tomar cuidado para que a equipe não gaste tempo excessivo analisando o problema e, após identificá-lo, parta para as soluções.

Para que seja estabelecido um plano de ações focando o problema central não deve ser esquecida a habilidade do grupo, estabelecimento de prazos, definições de responsabilidades, análises de custos e critérios para avaliação das ações. É muito importante a fase de planejamento, pois se procura traçar previamente o caminho que se deseja trilhar. 
O líder não deve esquecer-se de fornecer um feedback para sua equipe, ou seja, elogiar o que estiver sendo feito corretamente e treinar o que estiver sendo feito erroneamente.

b) Motivar:

O líder deve ser capaz de criar um ambiente propício à integração e ao trabalho coletivo, fazendo com que o grupo sinta-se disposto e estimulado em buscar um determinado objetivo. Neste sentido, o líder tem um papel fundamental e delicado perante a equipe, pois tem a responsabilidade de criar meios para que as pessoas sintam-se engajadas ao grupo e ajam como voluntários que lutam por uma causa nobre.

Como o trabalho de motivação é bastante difícil, o líder não deve esquecer-se de elogiar as pessoas. Segundo SHEILA BETHEL citada por OLIVEIRA e PAULETTI (WWW.CTAI.RCT-SC.Br), duas dicas são importantes: "Elogie em público - Corrija em particular" e "Encontre maneiras de elogiar todo seu pessoal não privilegiando apenas um integrante da equipe". Desta forma os membros do grupo estarão tendo o retorno do que fazem e poderão corrigir os erros durante a implementação das ações, deixando-os bastante a vontade para discussões e participações efetivas.

\section{c) Treinar:}

O treinamento é a chave para abrir o potencial das pessoas, motivá-las e detectar problemas para resolvê-los. É fundamental manter a equipe treinada.

Quando o líder estiver treinando seu pessoal, não deve pular os aspectos básicos, pois as revisões mantêm os funcionários "nos trilhos", diminui os problemas da falta de comunicação e reforça as metas a serem alcançadas. O líder deve procurar oferecer treinamentos práticos, específicos, breves, com diferentes técnicas e abordagens, avaliando o aprendizado de cada um. Devem ser enfatizados os benefícios pessoais que os treinamentos trarão. Quando um novo integrante vier a fazer parte da equipe, o líder deve avaliar seu conhecimento e experiência anterior e adequar os treinamentos necessários para que sejam niveladas as informações, de acordo com todos os 
membros do grupo. Os treinamentos devem ser feitos tão freqüentemente quanto possível, afim de que a equipe sinta-se motivada e comprometida.

É necessário ainda que o líder trabalhe e divulgue o significado do profissionalismo, pois todos os membros da equipe devem agir com responsabilidade na medida em que as decisões vão sendo tomadas. Portanto, o grupo deve procurar crescer e desenvolver suas habilidades técnicas e o relacionamento interpessoal.

d) Delegar:

Uma equipe se destaca efetivamente quando o líder é capaz de delegar, agindo de forma descentralizada, dividindo o trabalho entre a equipe $e$ procurando elevar a maturidade das pessoas através do repasse da responsabilidade e autoridade.

É importante lembrar que o líder que não delega transmite uma imagem de desconfiança a equipe. Portanto, o líder deve estar disposto a permitir que erros sejam cometidos na fase do aprendizado.

Ao designar um trabalho, o líder não deve dar a resposta imediata ao que deve ser feito, e sim, descrever os resultados esperados, dando oportunidade as pessoas pensarem sobre a tarefa e delimitando a autoridade sobre ela. Não se deve delegar responsabilidades sem dar autoridade.

É importante definir os prazos para apresentação dos resultados e prestação de contas, bem como monitorar o andamento das tarefas delegadas. Os membros da equipe devem sentir-se seguros no que estão fazendo, à vontade para perguntar e tirar dúvidas de suas atividades.

\section{Conclusão}

É necessário que seja trabalhada a antropologia da empresa, tão importante quanto à produtividade e a qualidade. Não adianta utilizar modelos de mudança e liderança, visando estritamente à produção, sem levar em consideração a cultura da empresa e os seus talentos humanos.

Atualmente as empresas estão buscando líderes que mobilizem a inteligência coletiva. As organizações necessitam de pessoas com forte visão estratégica, ou seja, com capacidade de pensar e assumir responsabilidades. 
$\mathrm{Na}$ realidade esta mudança no estilo de liderança, é a substituição do gerente que comanda pelo líder capacitador das pessoas. O líder deve mobilizar as pessoas nas organizações em direção aos objetivos propostos, e a chave para o sucesso é delegar poder a elas, dando-Ihes informações suficientes, fazendo com que pensem de forma integrada a equipe.

Segundo Hersey e Blanchard (1986), a liderança situacional é um instrumento que serve para ajudar as pessoas a compartilhar expectativas no seu ambiente, de modo que possam gradativamente aprender a supervisionar seu próprio comportamento e tornar as pessoas responsáveis e automotivadas.

\section{Bibliografia}

CHIAVENATO, Idalberto. Teoria Geral da Administração. São Paulo: Makron Books, 1993.

HERSEY, Paul e BLANCHARD, Keneth H. Psicologia para Administradores. São Paulo: EPU, 1986.

OLIVEIRA JR, José Neci Corrêa de e PAULETTI, Maurício Cappra. A Liderança em Equipes de Trabalho. CTAI - Centro de Tecnologia em Automação e Informática. <WWW.CTAI.RCT-SC.BR>, Acesso em 16/04/2001.

CABRAL, Claudio de Oliveira. Produtividade e Gente: O Possível Equilíbrio. CRA-RJ - Conselho Regional de Administração do Rio de Janeiro. WWW.CRA-RJ.ORG.BR> Acesso em 16/04/2001. 